\title{
ENERGY DISSIPATION AND LIQUEFACTION AT PORT ISLAND, KOBE
}

\author{
R.O. Davis ${ }^{1}$ and J.B. Berrill ${ }^{1,2}$
}

\begin{abstract}
SUMMARY
The Port Island, Kobe downhole records from the Hyogo-ken Nanbu earthquake are analysed to obtain approximate histories of shear stress, shear strain and dissipated energy at a range of depths. Our calculation method relies on measured accelerations in the horizontal plane to produce horizontal components of shear stress and strain using instantaneous modal superposition. A simple dissipated energy-dynamic pore pressure relationship is used to model the development of pore pressure leading to liquefaction. The results show a rapidly developing zone of liquefaction which initiates at a depth of roughly 15 metres in the Port Island reclaimed soils.
\end{abstract}

\section{INTRODUCTION}

Near the city of Kobe, a large area of reclaimed land called Port Island was subjected to intense ground shaking in the Hyogoken Nanbu earthquake of 17 January, 1995. Widespread liquefaction occurred in the reconstituted soils [1]. Prior to the earthquake an array of four strong motion instruments had been placed at various depths between the ground surface and $83 \mathrm{~m}$. Acceleration records were obtained in the North-South, EastWest, and vertical directions. These downhole records represent a valuable resource for study. They are the basis of this paper.

We will use a recently formulated interpolation model [2] to estimate shear stresses in the Port Island soils based on the measured accelerations. A similar scheme is used together with integrated displacements to estimate shear strains. We can then integrate stress and strain to find the amount of energy dissipated by the Port Island soils at any depth of interest. Time histories of dissipated energy normalised by overburden effective stress are presented. From these it appears dissipation was primarily confined to a single relatively narrow time band. It is also clear that while the soils softened dramatically, they did not completely lose all shear strength.

We will also present profiles of normalised dissipated energy for a range of different times. These profiles suggest a smooth distribution of dissipated energy, increasing to a peak at roughly the depth of the reconstituted layer. If we then postulate a dissipated energy - pore pressure increase relationship such as that described by Nemmat-Nasser and Shokooh [3], we can suggest at what depth and time liquefaction first occurred during the earthquake. We can also illustrate how the zone of liquefaction may have grown as shaking progressed. A complete picture of the liquefaction process is constructed.

The Hyogo-ken Nanbu earthquake has been extensively studied over the past two years and, to some extent, the work reported here repeats work done by others. In particular, estimates for stress and strain from Port Island have been carried out by Elgamal, et al. [4] and by Kazama [5]. The graphs of stress and strain that we present are similar to theirs, but cover a wider range of depths and are determined by a more accurate algorithm. The focus on dissipated energy which is a feature of our work has, so far as we know, not been repeated elsewhere.

\section{METHOD OF ANALYSIS}

Consider an array of four downhole instruments embedded in a layered soil profile as illustrated in Figure 1. The instruments are denoted $A, B, C$ and $D$ in order of increasing depth. We will refer to the instrument depths by $h_{A}, h_{B}$, etc. The measured acceleration at instrument $A$ will be denoted $a_{A}$, a function of time $t$, and the corresponding integrated displacement will be $u_{A}$, also a function of time. Similar notation will apply for the other instruments. As a first step toward estimating the stress and strain in the soil, we construct interpolating functions for both acceleration and displacement. At any particular value of $t$, the interpolating functions should be continuous functions of depth $x$ which pass through the measured acceleration or displacement values and which obey the boundary conditions of zero stress at the ground surface and boundedness as $x$ approaches infinity. The functions introduced in [2] are

$$
u(h, t, m)=\beta_{0}+\beta_{1} c_{1 h}^{m}+\beta_{2} c_{2 h}^{m}+\beta_{3} c_{3 h}^{m}
$$

for displacement and

$$
\ddot{u}(h, t, m)=\alpha_{1} c_{1 h}^{m}+\alpha_{2} c_{2 h}^{m}+\alpha_{3} c_{3 h}^{m}+\alpha_{4} c_{4 h}^{m}
$$

for acceleration. In both these expressions the index $m$ identifies the number of the soil layer, 1 being the uppermost or surface layer. The depth $h$ is measured from the upper surface

\footnotetext{
1 Department of Civil Engineering, University of Canterbury,

2 Fellow Christchurch.
} 
of the layer. The functions $c_{\lambda h}^{m}, \lambda=1, \ldots, 4$, are the first four terms in an eigenfunction expansion for the deformed shape of the layered halfspace. They are derived from a conventional, layered site response analysis. Effectively the $c_{\lambda h}^{m}$ represent modal shapes while the coefficients $\alpha_{\lambda}, \beta_{\lambda}$, $\lambda=1, \ldots, 4$, are weightings for each mode. A complete derivation of the $c_{\lambda h}^{m}$ may be found in [2].

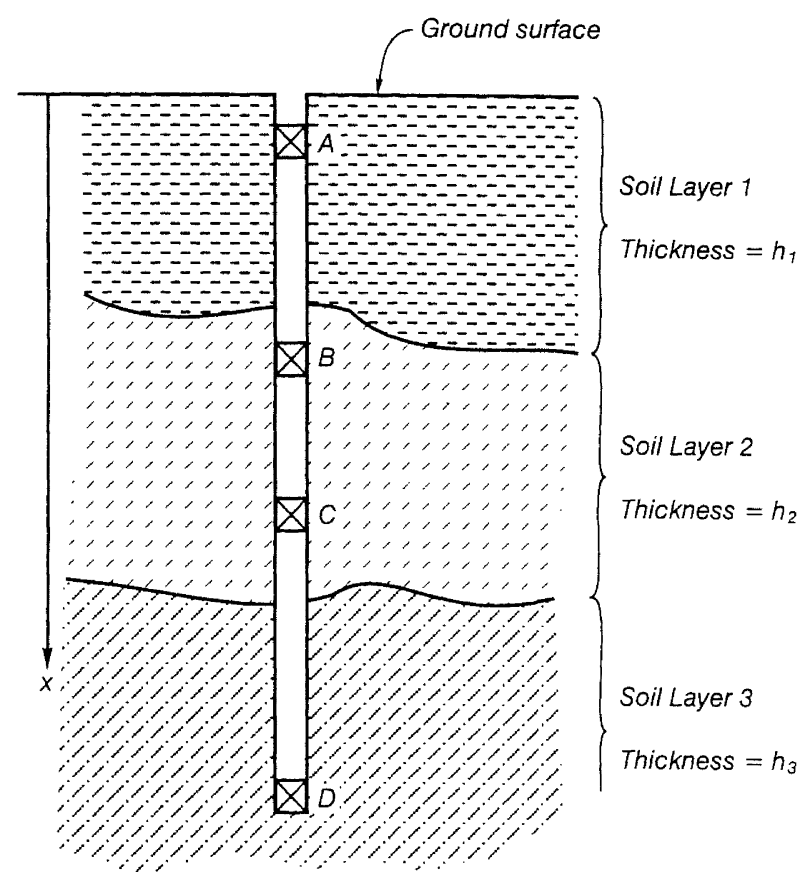

FIGURE 1: A typical downhole array. Instruments are denoted $A, B, C$ and $D$. Soil layers are numbered $1,2, \cdots$.

The coefficients $\alpha_{\lambda}, \beta_{\lambda}$ are functions of time. They are determined by the instantaneous values of displacement and acceleration. The inclusion of the coefficient $\beta_{o}$ in the displacement expansion where no similar term appears in the acceleration series occurs for reasons explained in [2]. At any time $t$, all of the coefficients $\alpha_{\lambda}, \beta_{\lambda}$ are found by solving two sets of simultaneous linear equations. For example, the coefficients $\beta_{\lambda}$ are determined by solving this set of equations

$$
\left[\begin{array}{llll}
1 & c_{1 A}^{m_{A}} & c_{2 A}^{m_{A}} & c_{3 A}^{m_{A}} \\
1 & c_{1 B}^{m_{B}} & c_{2 B}^{m_{B}} & c_{3 B}^{m_{B}} \\
1 & c_{1 C}^{m_{C}} & c_{2 C}^{m_{C}} & c_{3 C}^{m_{C}} \\
1 & c_{1 D}^{m_{D}} & c_{2 D}^{m_{D}} & c_{3 D}^{m_{D}}
\end{array}\right]\left\{\begin{array}{l}
\beta_{0} \\
\beta_{1} \\
\beta_{2} \\
\beta_{3}
\end{array}\right\}=\left\{\begin{array}{l}
u_{A} \\
u_{B} \\
u_{C} \\
u_{D}
\end{array}\right\}
$$

In this equation the notation $c_{1 A}^{m_{A}}$ for example refers to the eigenfunction expansion appropriate to the layer number $m_{A}$ which contains instrument $A$. The displacements $u_{A}, \cdots, u_{D}$ are the measured values at the time $t$. A similar set of equations involving the measured accelerations determines the $\alpha_{\lambda}$ coefficients.

Once the coefficients $\alpha_{\lambda}, \beta_{\lambda}$ have been determined for a particular value of $t$, the shear strain at any depth $h$ in any layer $m$ immediately follows from differentiating the interpolated displacement profile.

$$
\begin{aligned}
& \gamma(h, t, m)=\left[\frac{\partial u(x, t, m)}{\partial x}\right]_{x=h} \\
& =\left[\beta_{1} \frac{\partial c_{1 / h}^{m}}{\partial x}+\beta_{2} \frac{\partial c_{2 h}^{m}}{\partial x}+\beta_{3} \frac{\partial c_{3 h}^{m}}{\partial x}\right]_{x=h}
\end{aligned}
$$

Similarly we obtain the shear stress at depth $h$ in layer $m$ by integrating the acceleration profile. A separate integral is required for each layer.

$$
\begin{aligned}
& \tau(h, t, m)=\int_{0}^{h_{1}} \rho_{1} \ddot{u}(x, t, 1) d x+ \\
& \int_{0}^{h_{2}} \rho_{2} \ddot{u}(x, t, 2) d x+\cdots+\int_{0}^{h} \rho_{m} \ddot{u}(x, t, m) d x
\end{aligned}
$$

Note that in the last integral on the right, we can integrate to any desired depth $h$ within the layer. Since the eigenfunctions $c_{\lambda / 1}^{m}$ consist only of combinations of cosine terms, both the differentiations and the integrations shown above are easily performed in closed form. By applying equations (4) and (5) we can approximate the shear stress and strain at any particular values of depth and time within the layered soil profile.

Figure 2 shows an example of the interpolation functions for both displacement and acceleration. The situation illustrated is taken from the Port Island records. The ' + ' symbols on the figure represent measured instrumental values from the downhole array while the continuous lines show the interpolation functions derived from a three layer model. We will discuss the Port Island soil profile in more detail below, but it is useful to note here that the uppermost $19 \mathrm{~m}$ consisted of fill (primarily gravels), while a clay layer occurred between 19 and $27 \mathrm{~m}$. More gravels and sand were found under the clay. If one looks closely at Figure 2, discontinuous slopes on both the displacement and acceleration profiles may be observed at depths 19 and $27 \mathrm{~m}$. These occur at the interfaces between the different soil layers. They result naturally from the way the eigenfunction expansions $c_{\lambda h}^{m}$ are derived.

The profiles of displacement and acceleration shown on Figure 2 correspond to a particular time of $14.00 s$ on the Port Island records. By differentiating the displacement profile, or integrating the accelerations, we can approximate the shear strain and stress at any depth. The accuracy of our approximation will depend largely on the relative closeness of the downhole instruments. At Port Island the upper three 
instruments were placed at depths of 0,16 , and $32 \mathrm{~m}$. The fourth instrument was placed at $83 \mathrm{~m}$. We therefore would expect approximate values for stress and strain to be more accurate in the upper parts of the Port Island soils. This is fortunate since the liquefaction phenomena we wish to study occurred in the upper gravel layer. A more complete discussion of accuracy for our approximate method may be found in [2].
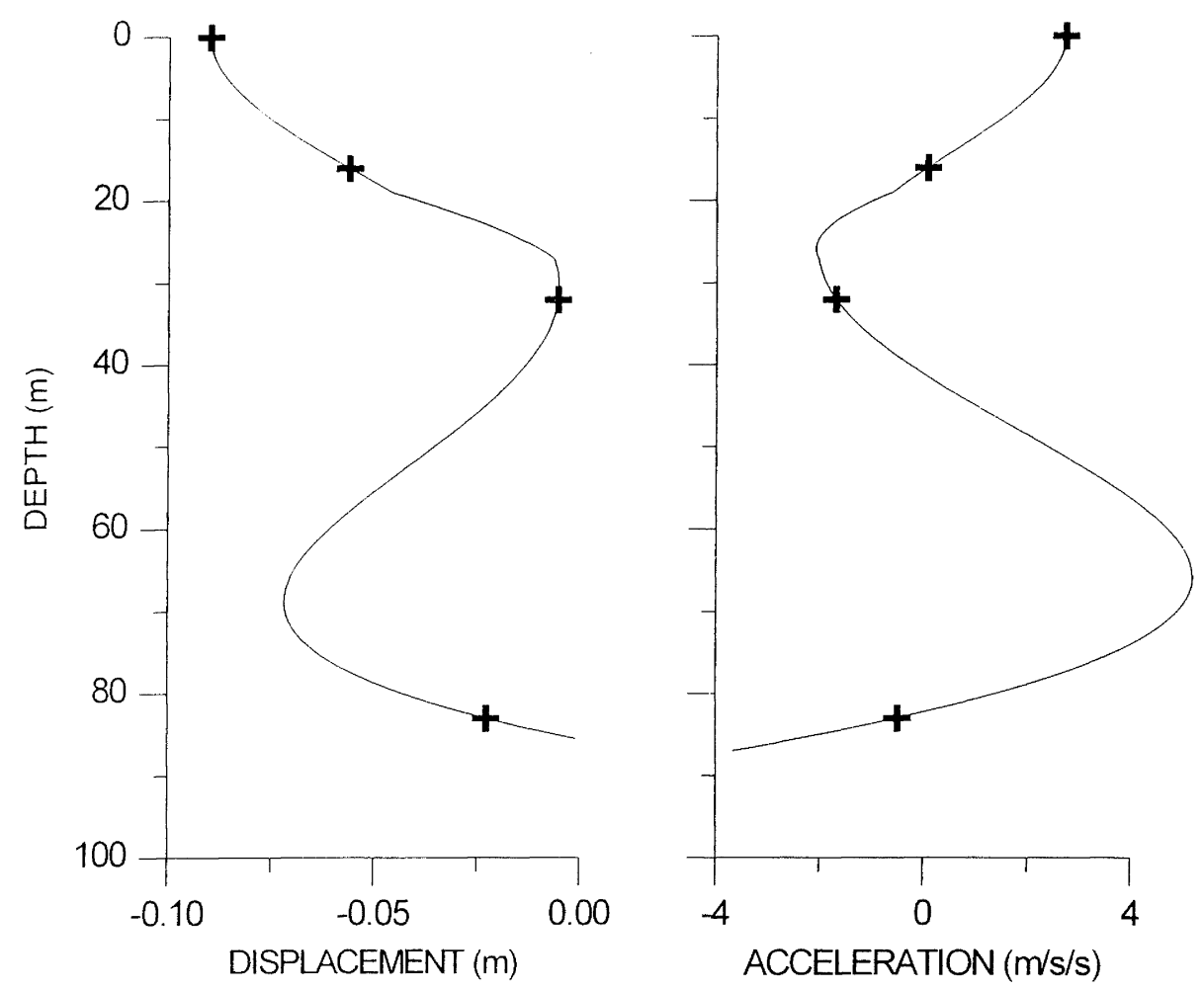

FIGURE 2: $\quad$ Profiles of displacement and acceleration constructed from the interpolation functions. '十' signs mark measured values.
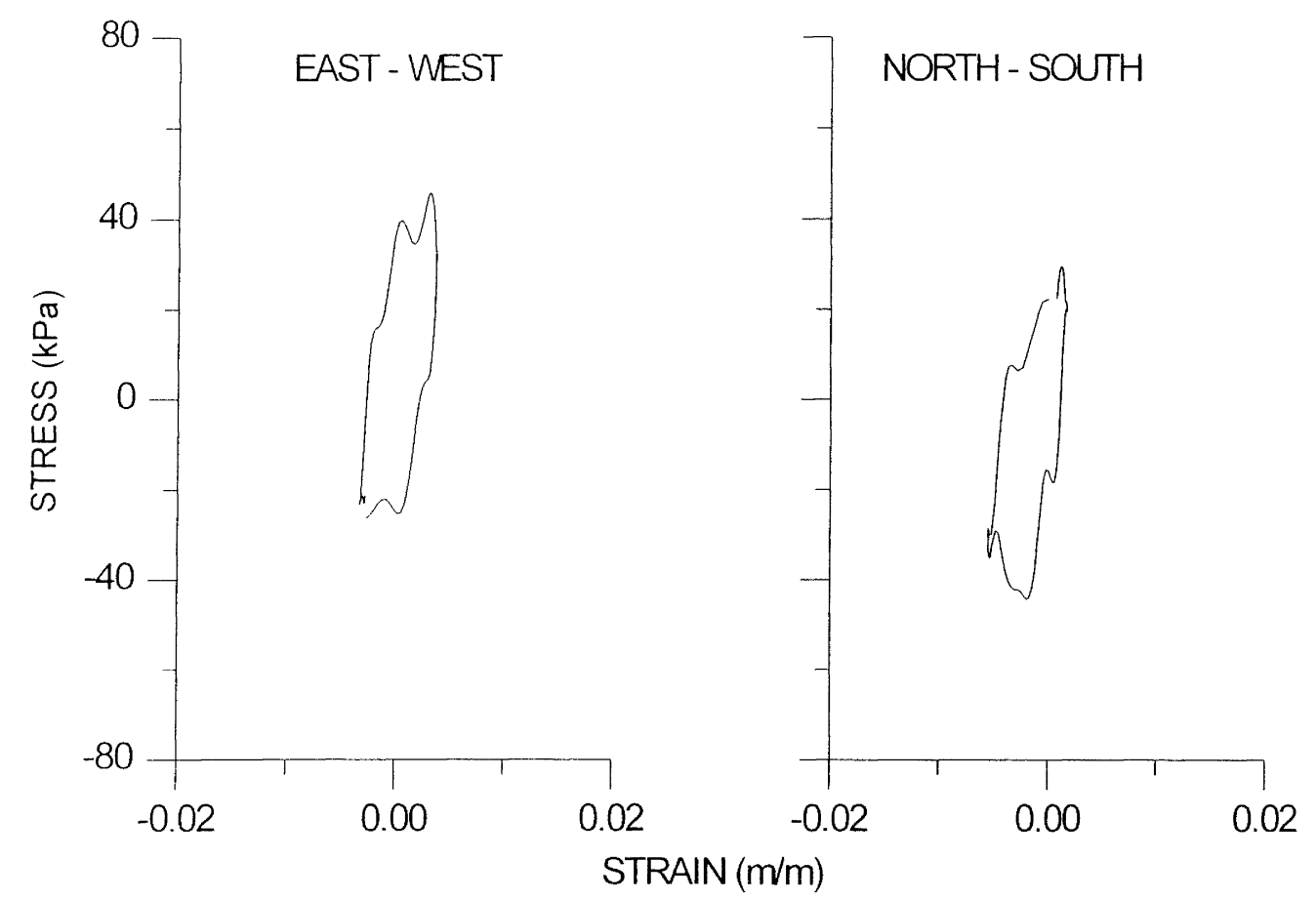

FIGURE 3: $\quad$ Typical shear stress-shear strain response approximated from the Port Island records. 


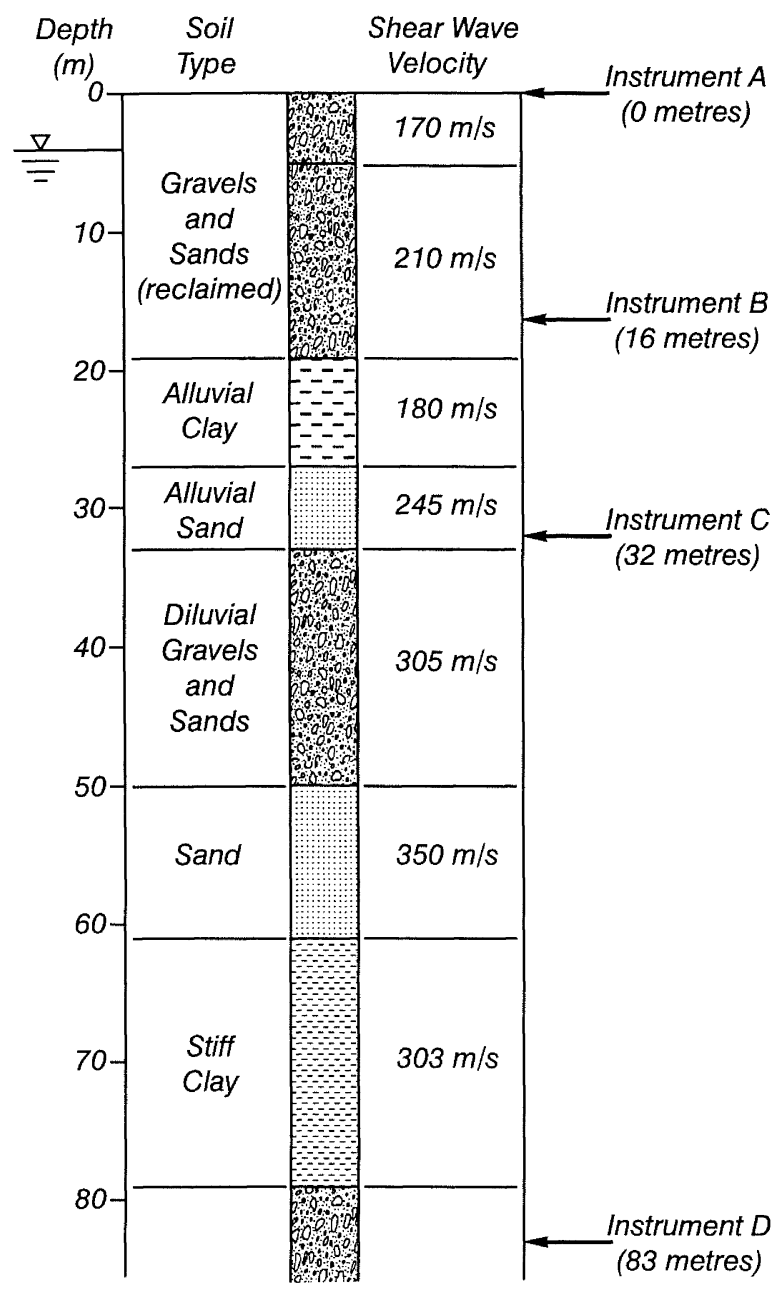

FIGURE 4: $\quad$ Port Island bore log. The shear wave velocities were obtained from geophysical logging of the bore.

If we determine the approximate shear stress and strain at a particular depth for a continuous sequence of times, we can create stress-strain curves such as those shown in Figure 3. These curves also represent data from Port Island. They corresponds to a depth of $12 \mathrm{~m}$ in the upper gravel layer and cover a time interval between $13.5 s$ and $14.35 s$ on the downhole records. Figure 3 is presented here to illustrate our analysis. The acceleration and displacement records will be examined in more detail below. Detailed accounts of stressstrain response will also be given later. We can readily determine the dissipated energy density $w$ corresponding to the approximated stresses and strains by integrating

$$
w(t)=\int_{0}^{t} \tau d \gamma
$$

The integral is easily carried out numerically using the stress and strain data generated from the acceleration and displacement records. For all the results presented below, $w$ is calculated by integrating both the North-South and East-West stress-strain response and summing the two. In this way $w$ represents the total dissipated energy density due to shearing deformation.

Finally, we will consider the possibility of a relationship between dissipated energy and the increase in pore pressure in the Port Island soils leading to liquefaction. Pore pressuredissipated energy dependence was first postulated by NematNasser and Shokooh [3]. Their idea was subsequently used by Davis and Berrill [6] and Berrill and Davis [7] to construct liquefaction risk analyses. Somewhat later, experimental studies were carried out $[8,9,10]$ which showed that in cyclic loading triaxial tests on saturated sands, pore pressures increased in a predictable way with dissipated energy. Two simple models of the pore pressure-dissipated energy relationship have been advanced $[6,7,9]$. The most simple is a linear relationship such as

$$
U=\frac{u}{\sigma^{\prime}}=\alpha \frac{w}{\sigma^{\prime}}=\alpha W
$$

Here $\alpha$ is a dimensionless constant relating the dimensionless pore pressure $U$ normalised by the initial overburden effective stress $\sigma^{\prime}$ to the normalised dissipated energy density $W=w / \sigma^{\prime}$. This model has obvious drawbacks, particularly when $U$ approaches 1 where complete liquefaction occurs and further increases in pore pressure are unlikely. A more plausible model is

$$
U=\beta W^{\xi}
$$

For appropriate values of the constants $\beta$ and $\xi$, reasonably good fits of laboratory experimental data are possible. Despite its limitations, the simple linear model of (7) is still useful, first because of the lack of sufficient experimental verification for the more complex model (8), second because it should give a conservative estimate of pore pressure increase. If the value of $U$ predicted by (7) does approach 1 , then we may feel that, despite the model's subsequent unrealistic behaviour, the pore pressure has reached a critical stage in the liquefaction process. Values of $\alpha$ in the range 50 to 80 are suggested by the existing experimental evidence.

\section{THE PORT ISLAND RECORDS}

Port Island was reclaimed by bottom dumping sand and gravel in roughly $15 \mathrm{~m}$ of water over a period of years beginning in 1966. A bore log from the site of the downhole array is shown in Figure 4. In the figure reconstituted soils lie above $19 \mathrm{~m}$ while naturally occurring soils are at greater depths. The water table was located at approximately $4 \mathrm{~m}$ depth. The bore was geophysically logged prior to installation of the downhole array and measured shear wave velocities are also shown on Figure 4. Complete details including SPT data may be found in Iwasaki and Tai [11].

In 1991 four three-component accelerometers connected to a common trigger were installed in the bore at the depths shown on Figure 4. Digitised acceleration records from the 
downhole array for the Hyogo-ken Nanbu earthquake were provided to us by the Committee of Earthquake Observation and Research in the Kansai Area. Figures 5 and 6 show a portion of the acceleration and integrated displacement time histories for both the East-West and North-South components of motion. The time interval covered by the two figures ranges between $12.5 s$ and $22.5 s$ on the digitised records. This interval covers the region of intense shaking.

A visual comparison of the acceleration records from different depths immediately suggests significant damping of higher frequency components has occurred in the upper soil layers, particularly in the uppermost $16 \mathrm{~m}$. This impression is strengthened from a simple analysis of the displacement time histories. On both Figures 5 and 6 there are clear cut concurrences of displacement peaks and valleys. By subtracting the arrival times of concurrent peaks and dividing by the distance between instruments we can obtain approximate values for shear wave velocities for the various regions between instruments. The procedure is summarised on Figures 7 and 8. For example, Figure 7 shows the EastWest displacement histories spaced vertically proportional to the corresponding instrument depths. Triangular marks have been attached to concurrent peaks and valleys. and lines have been sketched between. The apparent shear wave velocity is found by dividing the time interval between triangles by the vertical distance between instruments. There is of course some danger associated with this procedure in that reflections from the free surface or from interior boundaries may confuse the picture of peaks and valleys, but in both figures we have used only those extreme points which seem clear cut. The picture of shear wave velocities which emerges is surprisingly consistent. The velocity in the lower sediments between $83 \mathrm{~m}$ and $32 \mathrm{~m}$ is roughly $300 \mathrm{~m} / \mathrm{s}$, not dissimilar to the geophysical data shown on Figure 4. For the middle region between $32 \mathrm{~m}$ and $16 \mathrm{~m}$, an average velocity of about $150 \mathrm{~m} / \mathrm{s}$ is evident. It is in the uppermost region, however, that a striking decrease in velocity is clear. For both the East-West and the NorthSouth records we see an initial velocity of roughly $250 \mathrm{~m} / \mathrm{s}$ decreasing to roughly $45 \mathrm{~m} / \mathrm{s}$ at about $15 s$, and then further decreasing to about $25 \mathrm{~m} / \mathrm{s}$ later in the record. It's clear the upper reconstituted soils suffered significant softening during the earthquake. It's also clear, however, that the upper layer did not totally lose all shear strength. It will be convenient to refer back to Figures 7 and 8 when we consider the dissipated energy profiles later in the paper.

\section{STRESS-STRAIN RESPONSE}

In this section we will consider three time intervals during the shaking which are of particular interest. The intervals are $13.5 s$ to $14.35 s, 14.4 s$ to $16.2 s$, and $17.8 s$ to $20.3 s$. The first interval covers the first significant acceleration pulse and the initial softening of the upper gravels. During the second interval the softening is intensified and large deformations occur. The third interval considers a period during which the upper gravels are extremely soft. All three time intervals have been selected to illustrate particular features of the stressstrain response, especially for the North-South records. The calculations illustrated below are all based on a three layer representation of the Port Island soil profile.

Figures 9 and 10 show stress-strain behaviour at various depths for both East-West and North-South motions. Both figures show stress and strain at six different depths: $4 \mathrm{~m}, 8 \mathrm{~m}$, $12 \mathrm{~m}$, and $16 \mathrm{~m}$ in the upper reclaimed soils, and $20 m$ and 24 $m$ in the alluvial clay layer. The scales of all the plots are the same to facilitate visual comparisons and the time intervals are noted on the left-hand plots of each figure. Together the figures present a relatively complete picture of the soil response during the earthquake.

Considering Figure 10a first, we see at $4 m$ depth relatively small scale stresses and strains which describe well defined hysteresis loops during the three time intervals. The loops differ markedly in terms of the range of stress and especially strain, with the response being fairly stiff between 13.5 and $14.35 \mathrm{~s}$, becoming extremely soft between 17.8 and $20.3 \mathrm{~s}$. Moving down to the $8 m$ depth we see a general magnification of both stress and strain without much change in shape of the loops. The magnification is expected since the $4 \mathrm{~m}$ depth is in closer proximity to the stress free ground surface. Continuing to Figure $10 \mathrm{~b}$, we see still more magnification but roughly similar shapes for the hysteresis loops. At the $16 \mathrm{~m}$ depth relatively large values of stress in excess of $50 \mathrm{kPa}$ are evident during the first two time intervals. Finally consider Figure 10c. Both depths represented on this figure lie within the clay layer. At the $20 \mathrm{~m}$ depth, considerable similarity to the response in the gravel layer is evident; however, at $24 \mathrm{~m}$, the behaviour is significantly different and much more elastic in nature.

Figure 9 shows similar plots based on the East-West motion. For the 13.5-14.35 $s$ interval, remarkably similar response to the North-South data is observed. At later times the response is vaguely similar but the hysteresis loops are not so well defined as in the North-South case. To some extent this is due to our selection of times. The three time intervals were specifically selected to isolate the hysteretic behaviour seen in the North-South data. As a result, less well organised response is evident for the East-West data. However, the same overall picture emerges from Figure 9. Significant amounts of softening clearly occurred, except near the centre of the clay layer where more or less elastic response is seen.

\section{ENERGY DISSIPATION}

Finally we can consider the dissipated energy density associated with the stress-strain response. Figure 11 shows graphs of normalised dissipated energy $W$ for increments of depth of $1 \mathrm{~m}$ throughout the reclaimed layer for all times between $12.5 s$ and $22.5 \mathrm{~s}$. In constructing these time histories we have estimated the effective stress based on a uniform submerged density of $0.80 \mathrm{t} / \mathrm{m}^{3}$. While this does not adequately account for the soil above the water table, the overall effect on the plotted data is small. Also shown on this figure are the three time intervals for which the stress-strain plots were made denoted by A, B and C. Each of the 18 curves plotted refers to one particular depth and the depth values are indicated on the right hand side of the graph. The highest of the curves corresponds to a depth of $13 \mathrm{~m}$. For greater depths the amount of dissipation decreases, and the curves for 14 through $18 \mathrm{~m}$ depths are indicated by dashed lines.

It is clear from Figure 11 that relatively little dissipation occurs during time interval A. Most of the dissipation 
happens during interval $\mathrm{B}$, corresponding to the largest hysteresis loops on Figures 9 and 10. A third episode of dissipation can be seen as a step in $W$ near the centre of interval $\mathrm{C}$.

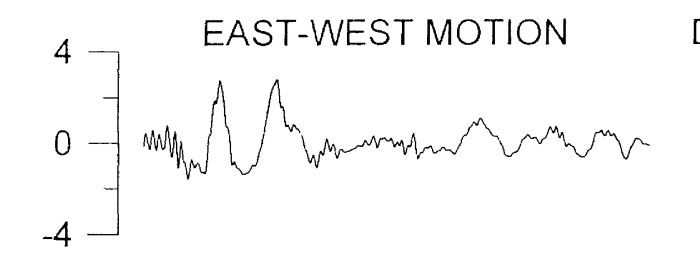

DEPTH

$0 m$

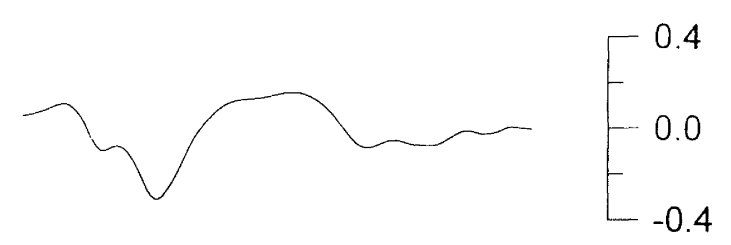

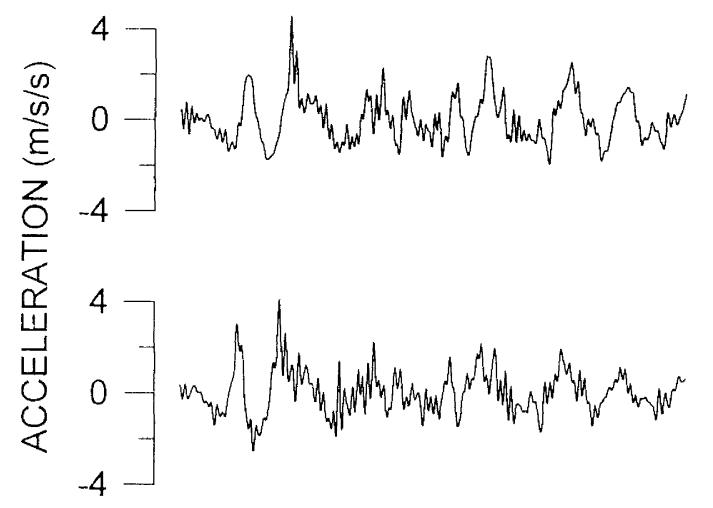
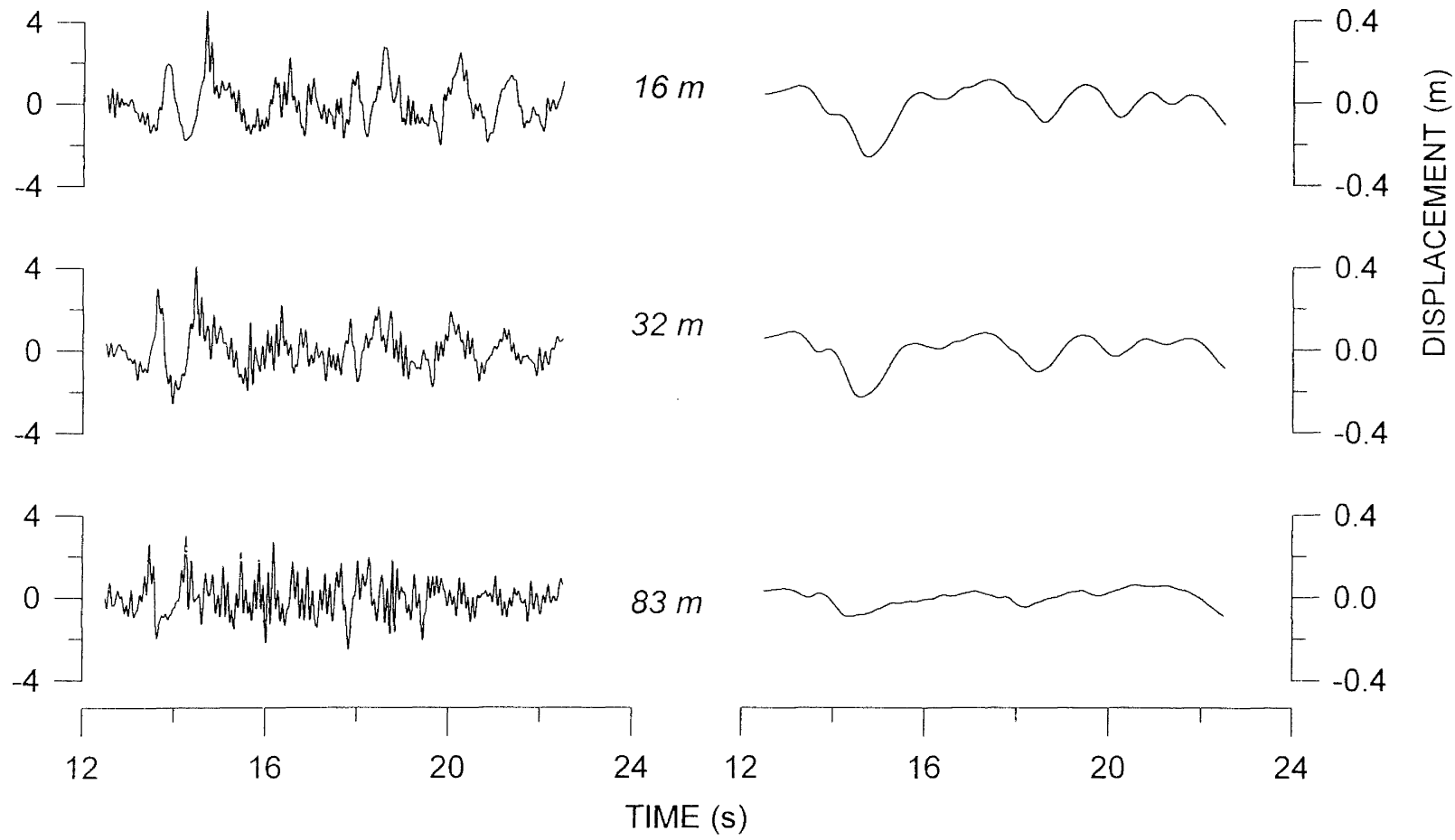

FIGURE 5: $\quad$ Measured East-West accelerations and integrated displacements for the four downhole instruments at Port Island. 

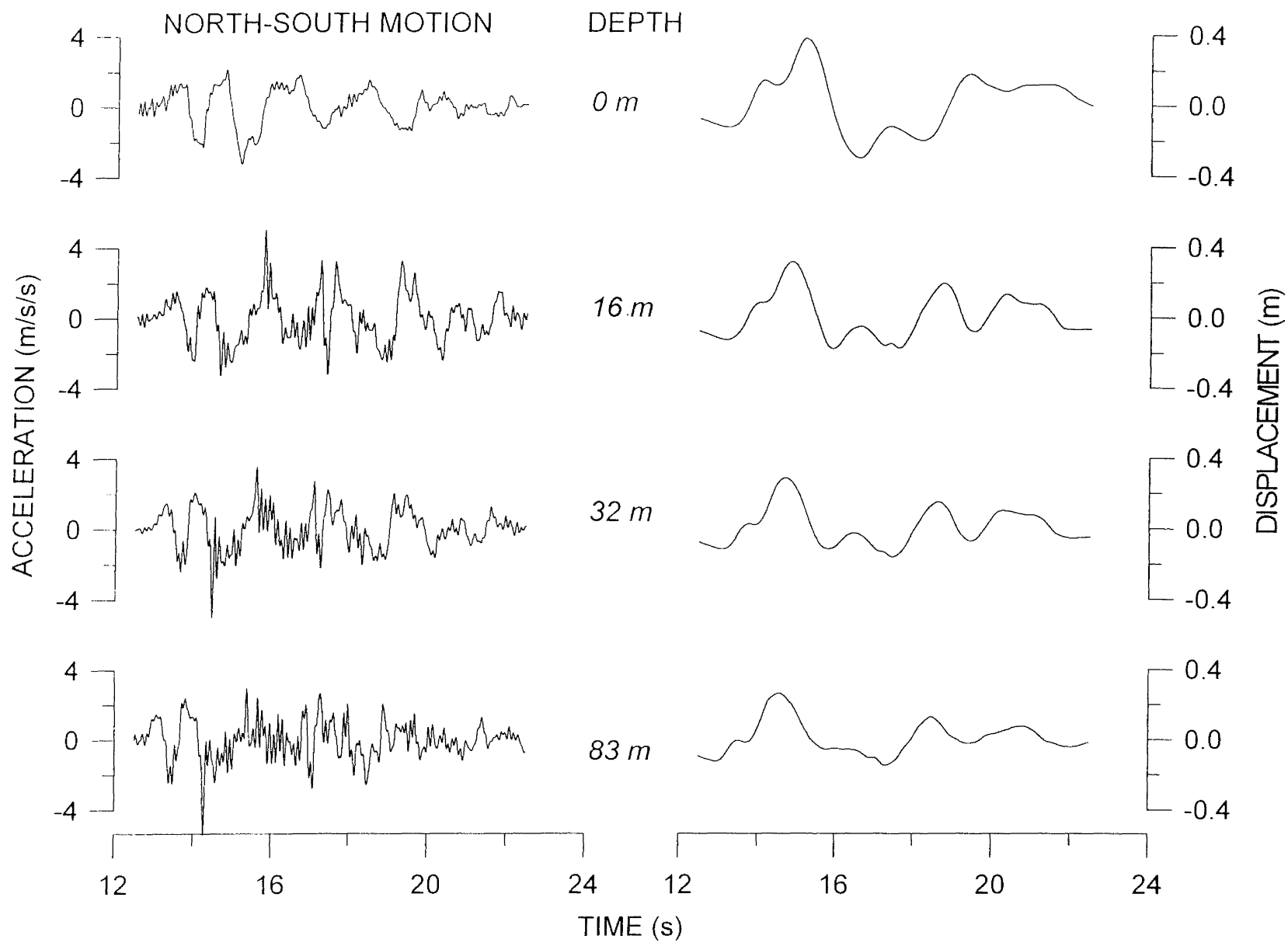


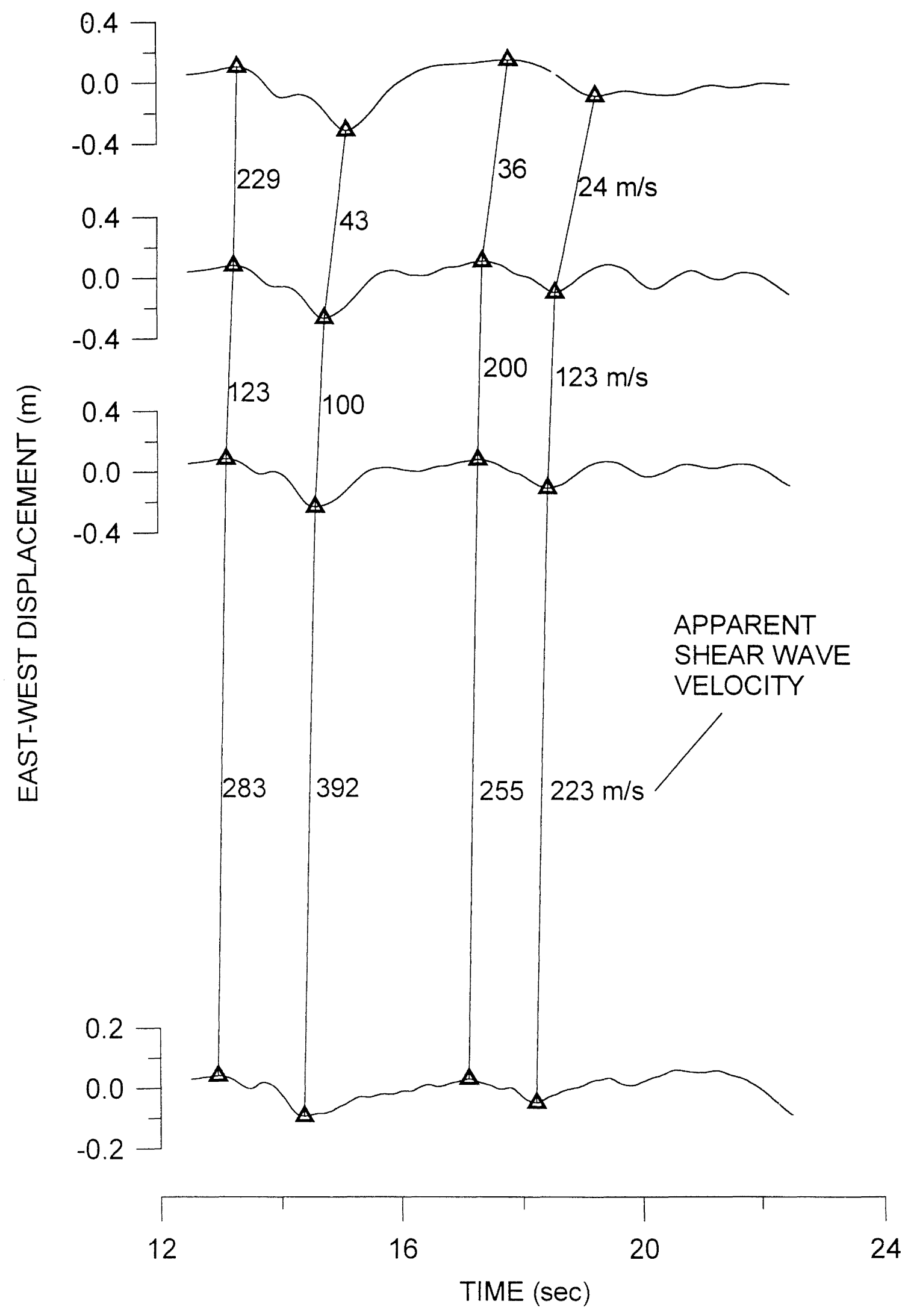

FIGURE 7: East-West displacement histories with concurrent peaks and valleys connected. The apparent shear wave velocities are obtained by dividing the instrument separations by the measured time lags. 


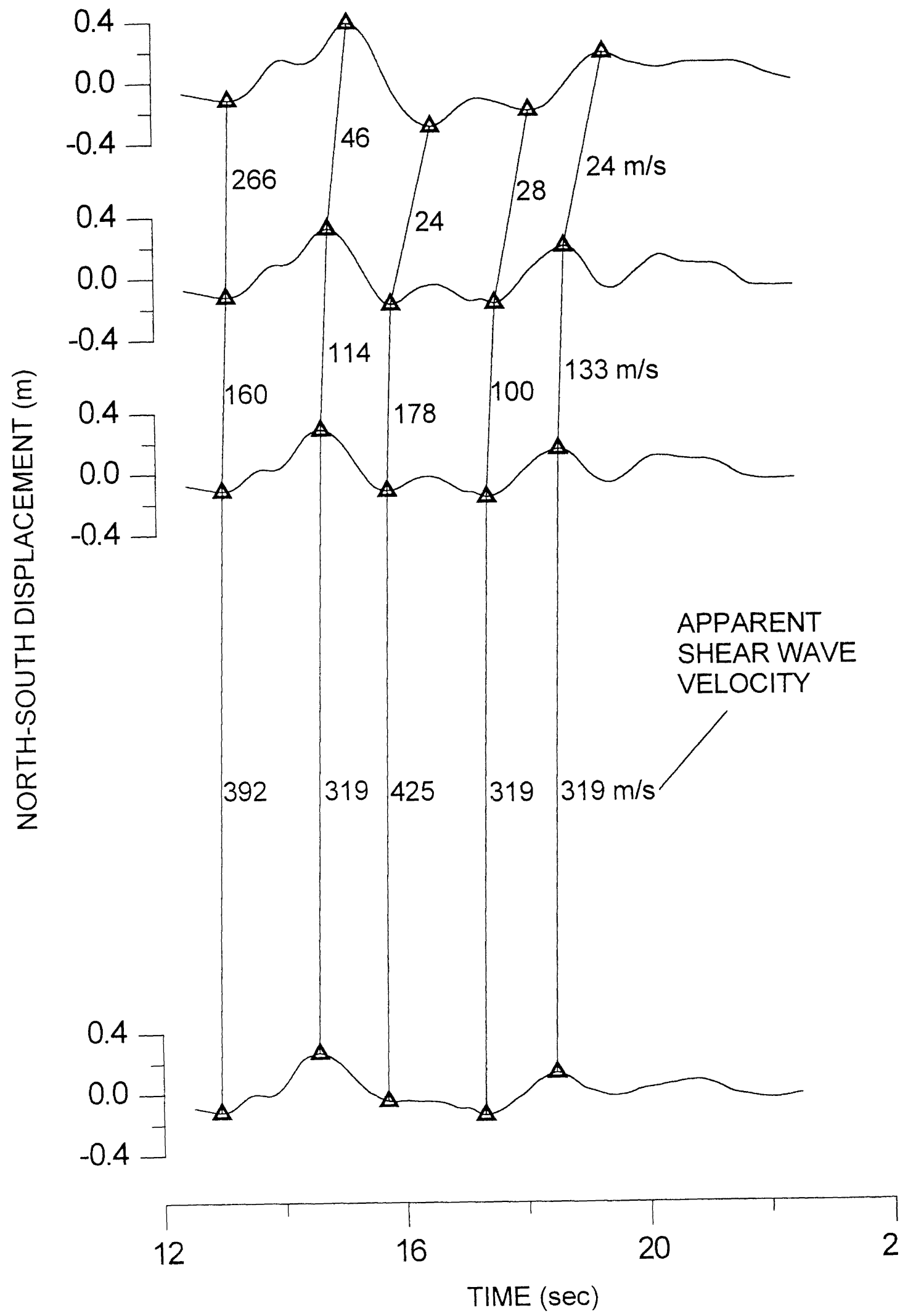

FIGURE 8: $\quad$ Similar to Figure 7 but for North-South data. 


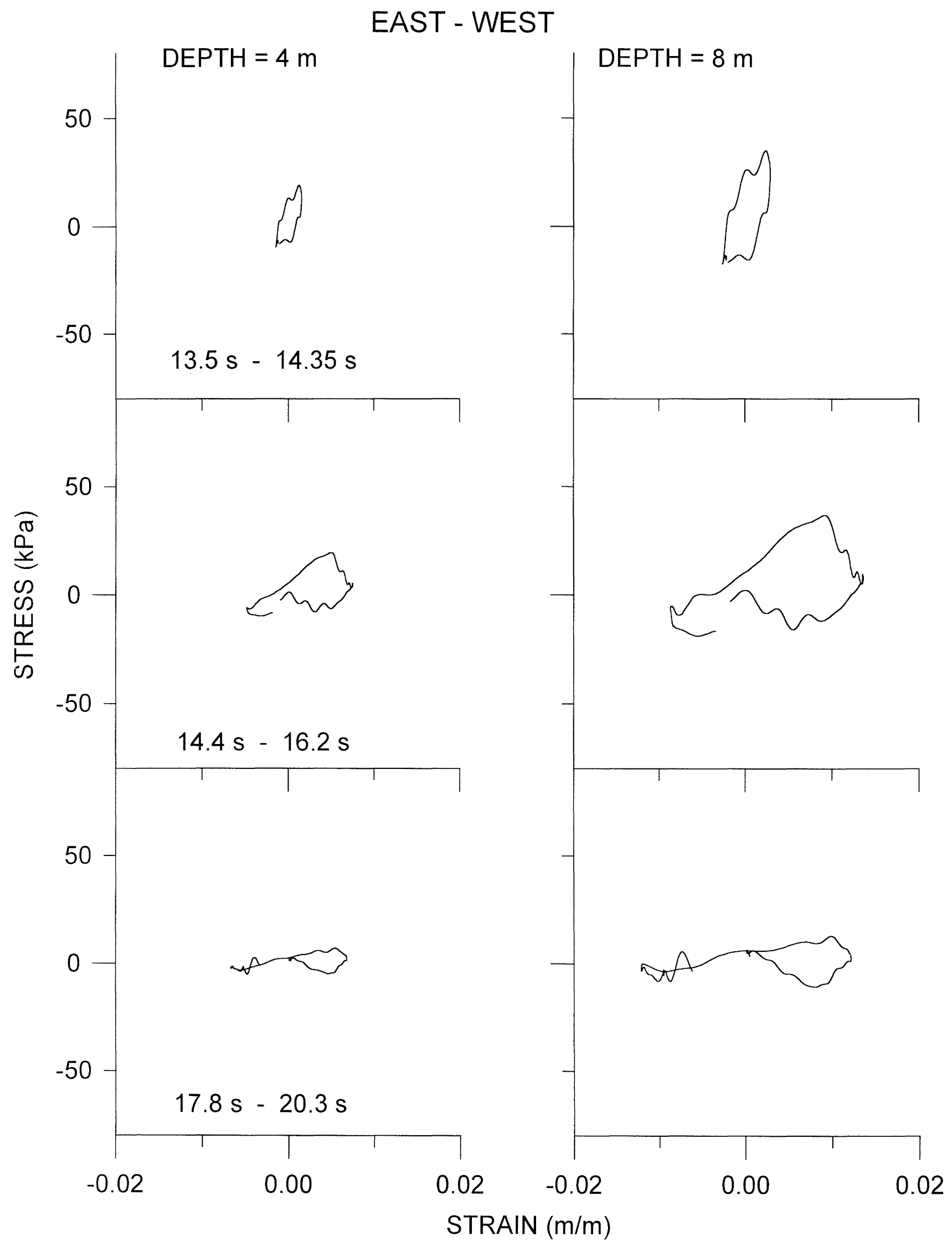

FIGURE 9: $\quad$ Shear stress-shear strain response in the East-West direction at various depths and times. 


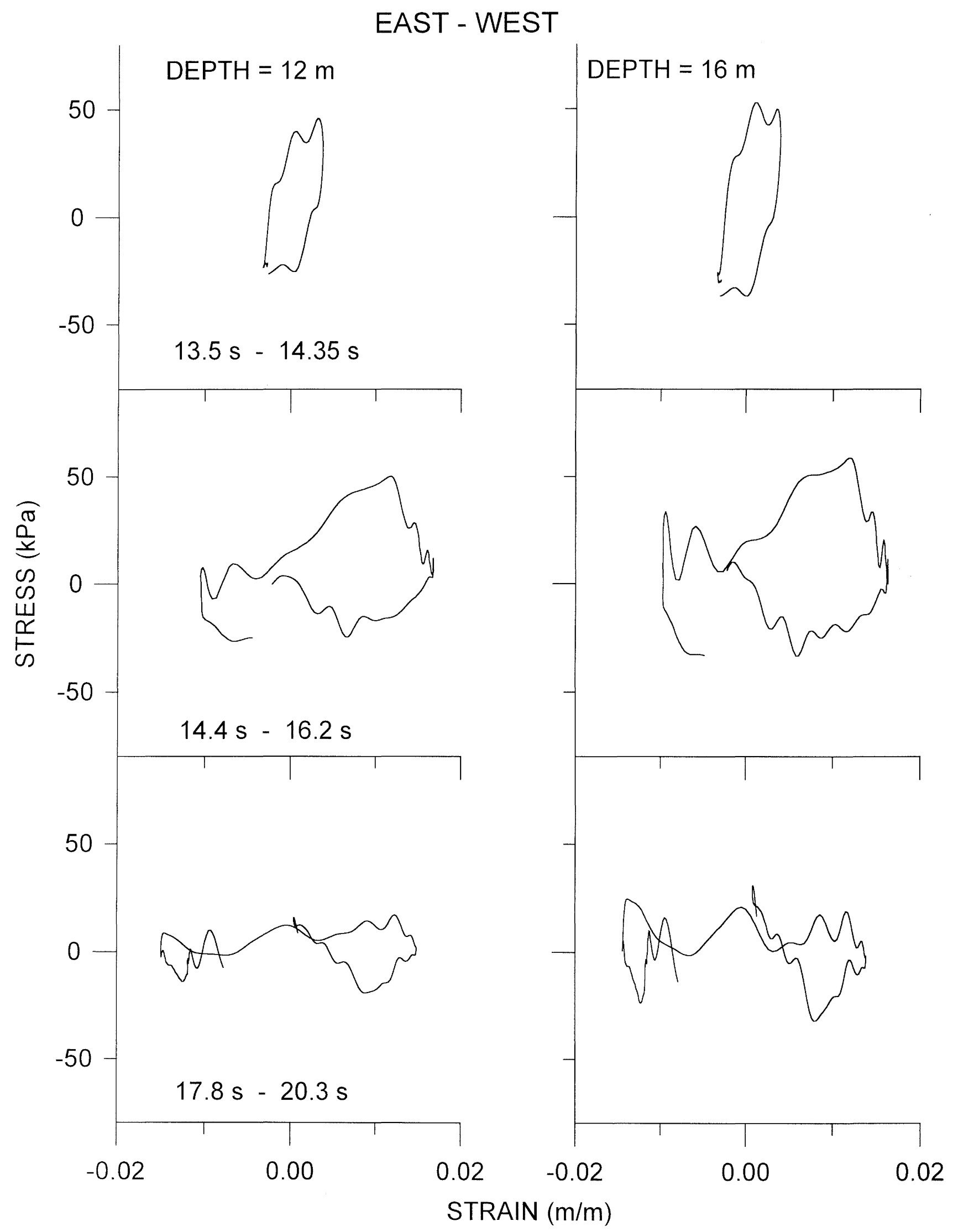

FIGURE 9 continued: $\quad$ Shear stress-shear strain response in the East-West direction at various depths and times. 


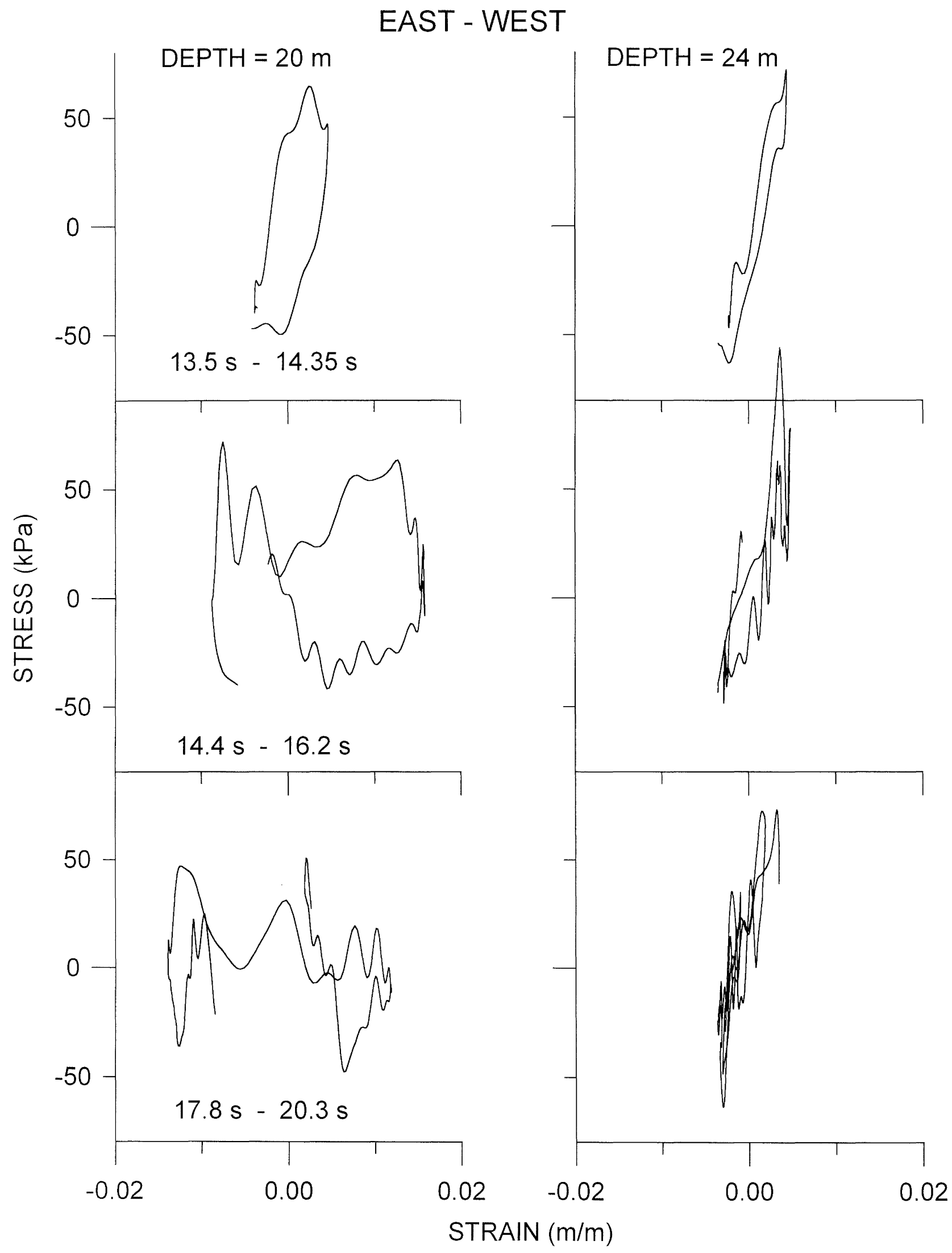




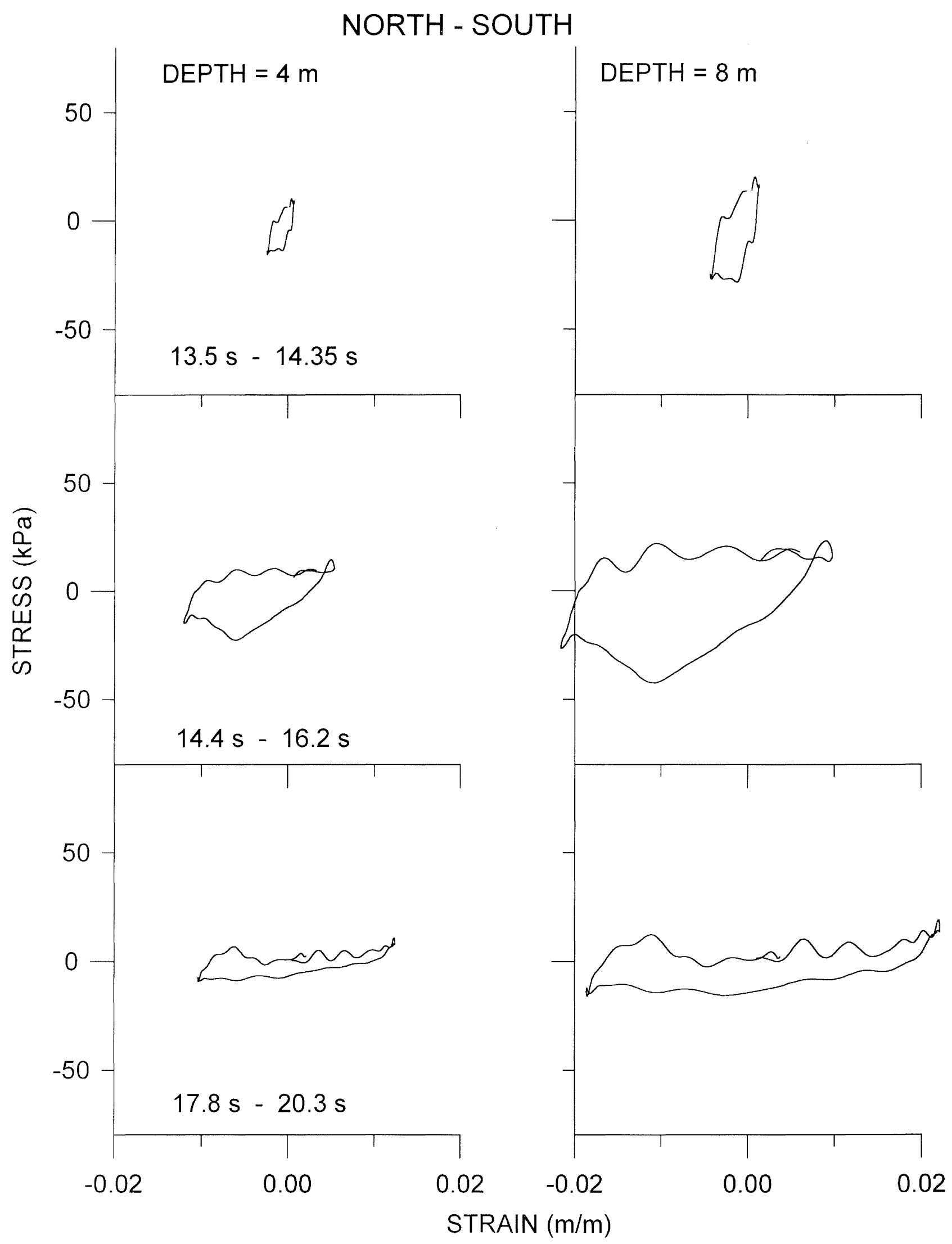

FIGURE 10: Shear stress-shear strain response in the North-South direction at various depths and times. 


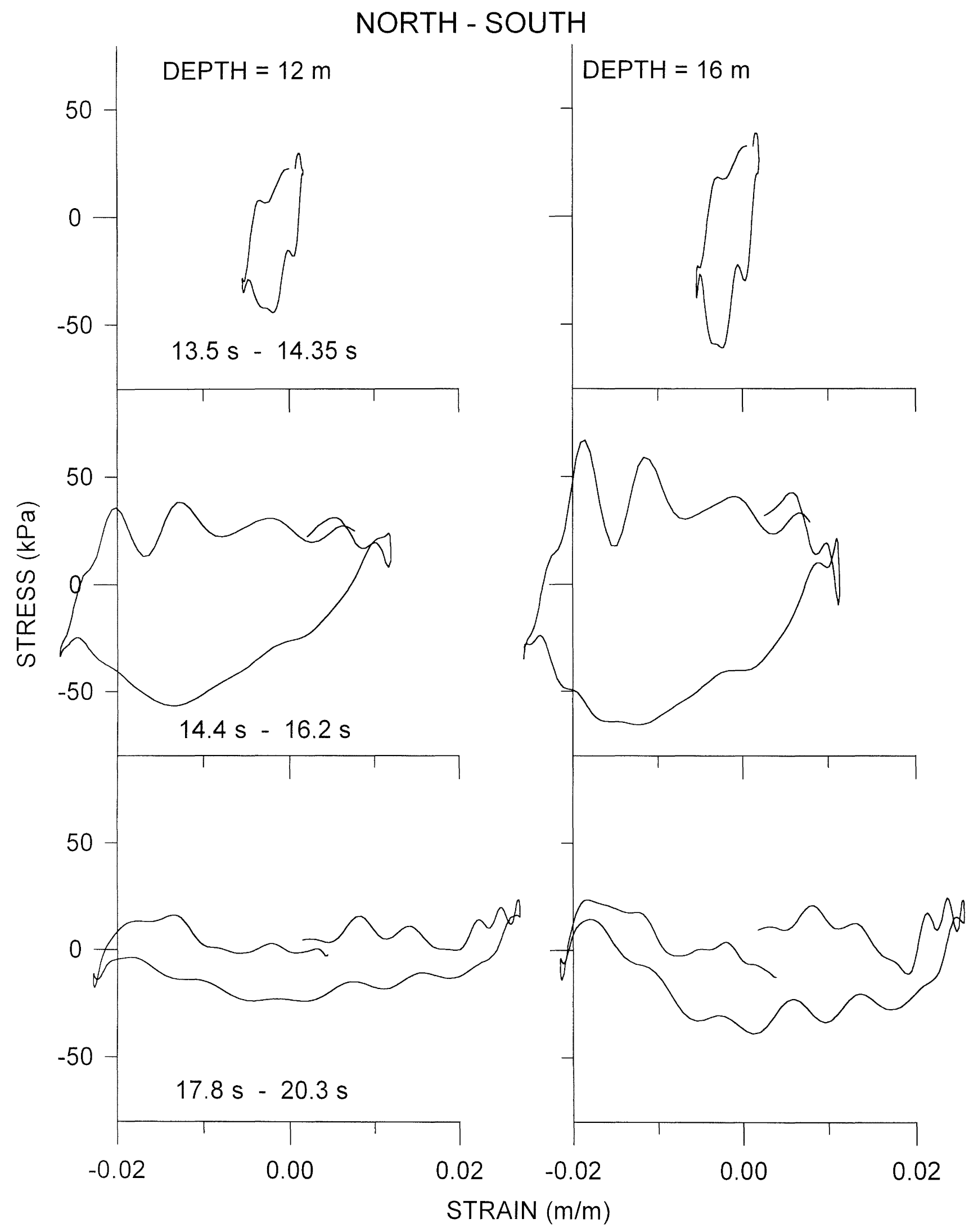

FIGURE 10 continued: Shear stress-shear strain response in the North-South direction at various depths and times. 


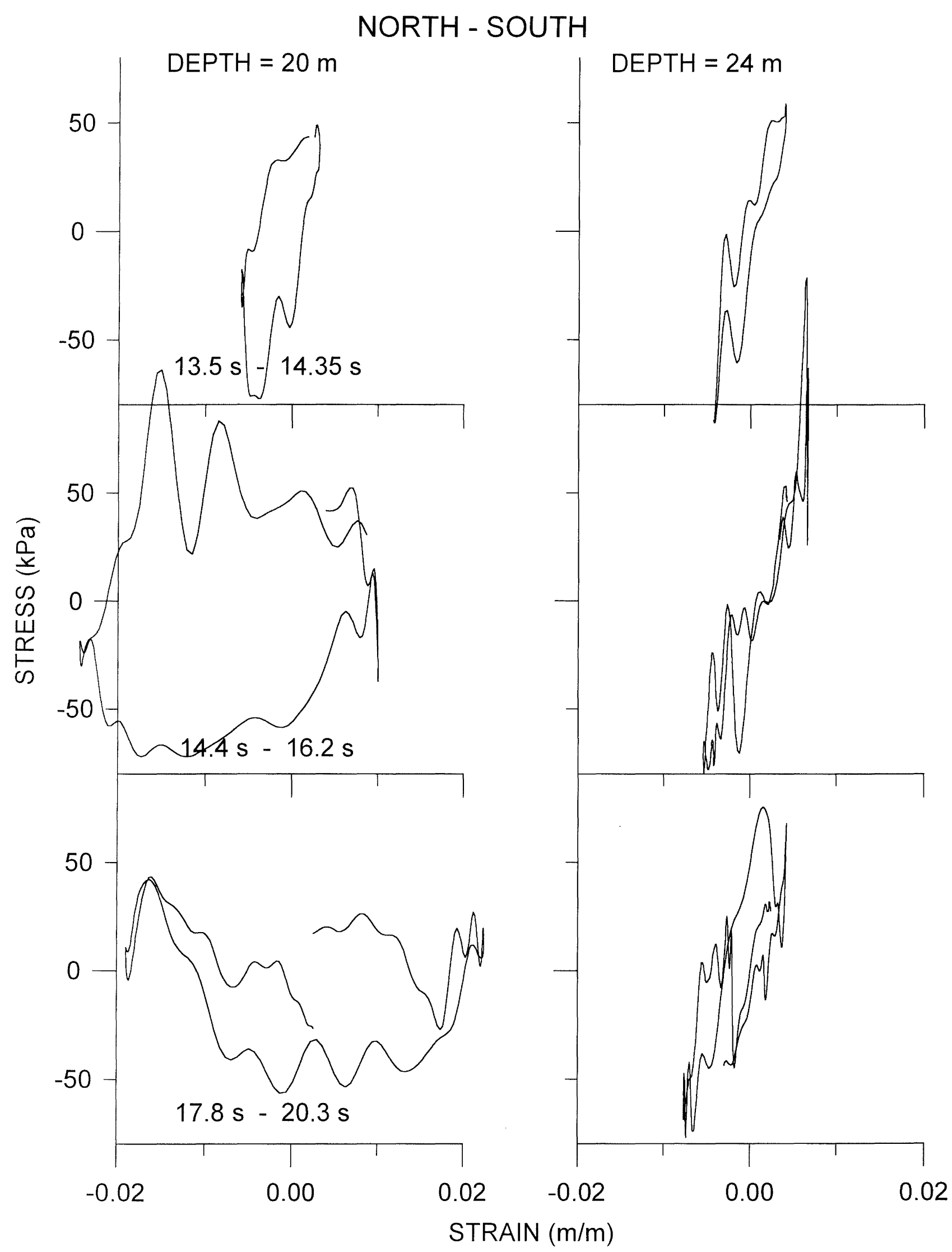

FIGURE 10 continued: Shear stress-shear strain response in the North-South direction at various depths and times. 
We can also construct vertical profiles of $W$ for various times $t$. A selection of profiles are shown in Figure 12. A total of nine profiles are plotted beginning at $t=14 \mathrm{~s}$ and increasing in increments of one second. These profiles seem remarkable for their smoothness but this is in fact a reflection of the smoothness of our interpolating functions. It is again clear from this figure the bulk of the dissipation happens between 14 and $16 \mathrm{~s}$. The dissipation step noted in interval $\mathrm{C}$ on Figure 11 is also evident between 19 and $20 \mathrm{~s}$.

It is now interesting to conjecture on the occurrence of liquefaction in the layer. Recalling our discussion concerning the relationship between pore pressure increase and dissipated energy, we note that the normalised pore pressure $U$ could be expected to approach a value of 1 (indicating liquefaction) when the value of $W$ nears $1 / \alpha$. The range of values of $\alpha$ suggested by laboratory tests is 50 to 80 . Thus we might expect the onset of liquefaction to occur when $W$ enters the range $1 / 80=0.0125$ to $1 / 50=0.02$. This range of values is highlighted on Figure 12. The graph suggests dissipated energy density in the soil crosses the liquefaction threshold at a depth of roughly $15 \mathrm{~m}$ and at some time near $15 \mathrm{~s}$. A zone of liquefaction would then extend upward and downward. We can easily follow the progress of this zone as shown in Figure 13. The two lines trace the development of the liquefied zone for either of the two $\alpha$ values. Referring to the $\alpha=80$ case, we see the zone of liquefaction quickly moves downward to the base of the gravel layer. It also moves upward to a depth of roughly $4 \mathrm{~m}$ and then increases much more slowly. In reality the water table is near $4 \mathrm{~m}$ and liquefaction would be impossible above that point. The line corresponding to $\alpha=50$ has a similar shape to that for the larger value but the onset of liquefaction occurs slightly later and the propagation of the zone is slightly slower.

If we compare the results shown in Figure 13 with the apparent shear wave velocities shown in Figures 7 and 8, a coherent picture emerges. By a time of roughly $15 s$, the shear wave velocity has decreased to about $45 \mathrm{~m} / \mathrm{s}$ indicating considerable softening has occurred in the reclaimed layer. Also, by that time, the dissipated energy has neared the liquefaction threshold. Within the next two seconds liquefaction has evidently developed over a significant part of the layer and the shear wave velocity has decreased to roughly $30 \mathrm{~m} / \mathrm{s}$. Clearly the dissipated energy-liquefaction model yields results which are in broad agreement with the apparent wave velocity calculations.

As a final remark, we note that complete liquefaction with associated total loss of shear strength clearly did not occur. This is evident from the shear wave velocities being small but clearly not zero, as well as from the dissipation time histories which show that even quite late in the shaking the soil was capable of propagating distorsional energy upward through the layer. There are two likely reasons behind this. First, there was no impervious layer lying above the liquefied soil. Second, the soil is described as a gravel or a gravelly sand and is presumably quite permeable. The combination of these two things suggests that pore pressures could rapidly dissipate due to upward flow.

\section{CONCLUSION}

We have attempted to analyse the Port Island downhole acceleration records with the aim of estimating shear stresses and strains, and energy dissipation in the reconstituted soils. A coherent picture of softening of the soil is found. The approximated stress-strain curves clearly indicate significant softening as shaking progresses. If we integrate these curves, time histories of dissipated energy density may be constructed. They show that most of the energy absorbed by the soil happens in a single narrow band of time. During this time interval the shear wave velocity appears to decrease by roughly an order of magnitude and we conjecture that sufficient excess pore pressure has been generated to induce at least partial liquefaction. At the same time the dissipated energy density crosses the liquefaction threshold value found from laboratory cyclic loading tests. All the data we have presented point to a clear picture of liquefaction. The dissipated energy model also permits us to estimate exactly how liquefaction may have developed in the reclaimed soils. Liquefaction probably initiated near the $2 / 3$ depth of the layer and then rapidly propagated upward to near the ground surface, and simultaneously downward to the interface with the underlying clay layer.

\section{ACKNOWLEDGEMENT}

We are grateful to Dr. Yoshinori Iwasaki and the Committee of Earthquake Observation and Research in the Kansai Area (CEORKA) for making the Port Island records available to us.

\section{REFERENCES}

1. Shibata, T., Oka, F. and Ozawa, Y. (1996), Characteristics of ground deformation due to liquefaction, Soils and Foundations, Special Issue for Kobe Earthquake, pp. 65-97.

2. Davis, R.O. and Berrill, J.B., Rational approximation of shear stress and strain based on downhole acceleration records, Int. Jour. Num. Anal. Methods Geomech., submitted for publication.

3. Nemat-Nasser, S., and Shokooh, A. (1979), A unified approach to densification and liquefaction of cohesionless sand in cyclic shearing, Canadian Geotech. Jour., 16, 659-678.

4. Elgamal, A.-W., Zeghal, M., and Parra, E. (1996), Liquefaction of reclaimed land in Kobe, Japan, Jour. Geotech. Engg., ASCE, 122, No. 1, pp. 39-49.

5. Kazama, M. (1996), Nonlinear behaviour of the ground inferred from strong motion array records at Kobe Port Island during the 1995 Hyogo-ken Nanbu Earthquake, Proc. Int. Workshop on Site Response, Port and Harbour Research Institute, Yokosuka, Japan, pp.185-199.

6. Davis, R.O., and Berrill, J.B. (1982), Energy dissipation and seismic liquefaction in sands, Earthq. Engg. Struct. Dyns., 10, 59-68. 
7. Berrill, R.O. and Davis, R.O. (1985), Energy dissipation and seismic liquefaction in sands: Revised model, Soils and Foundations, 25, no. 2, 106-118.

8. Simcock, K.J., Davis, R.O., Berrill, J.B., and Mullenger, G. (1983), Cyclic triaxial tests with continuous measurement of dissipated energy, Geotech. Testing Jour., 6, 35-39.

9. Law, K.T., Cao, Y.L., and He, G.N. (1990), An energy approach for assessing seismic liquefaction potential, Canadian Geotech. Jour., 27, 320-329.

10. Figueroa, J.L., Saada, A.S., Liang, L., and Dahisaria, M.N. (1994), Evaluation of soil liquefaction by energy principles, Jour. Geotech. Engg. Div., ASCE, 120, 15541569.

11. Iwasaki, Y., and Tai, M. (1996), Strong motion records at Kobe Port Island, Soils and Foundations, Special Issue for Kobe Earthquake, pp. 29-40.

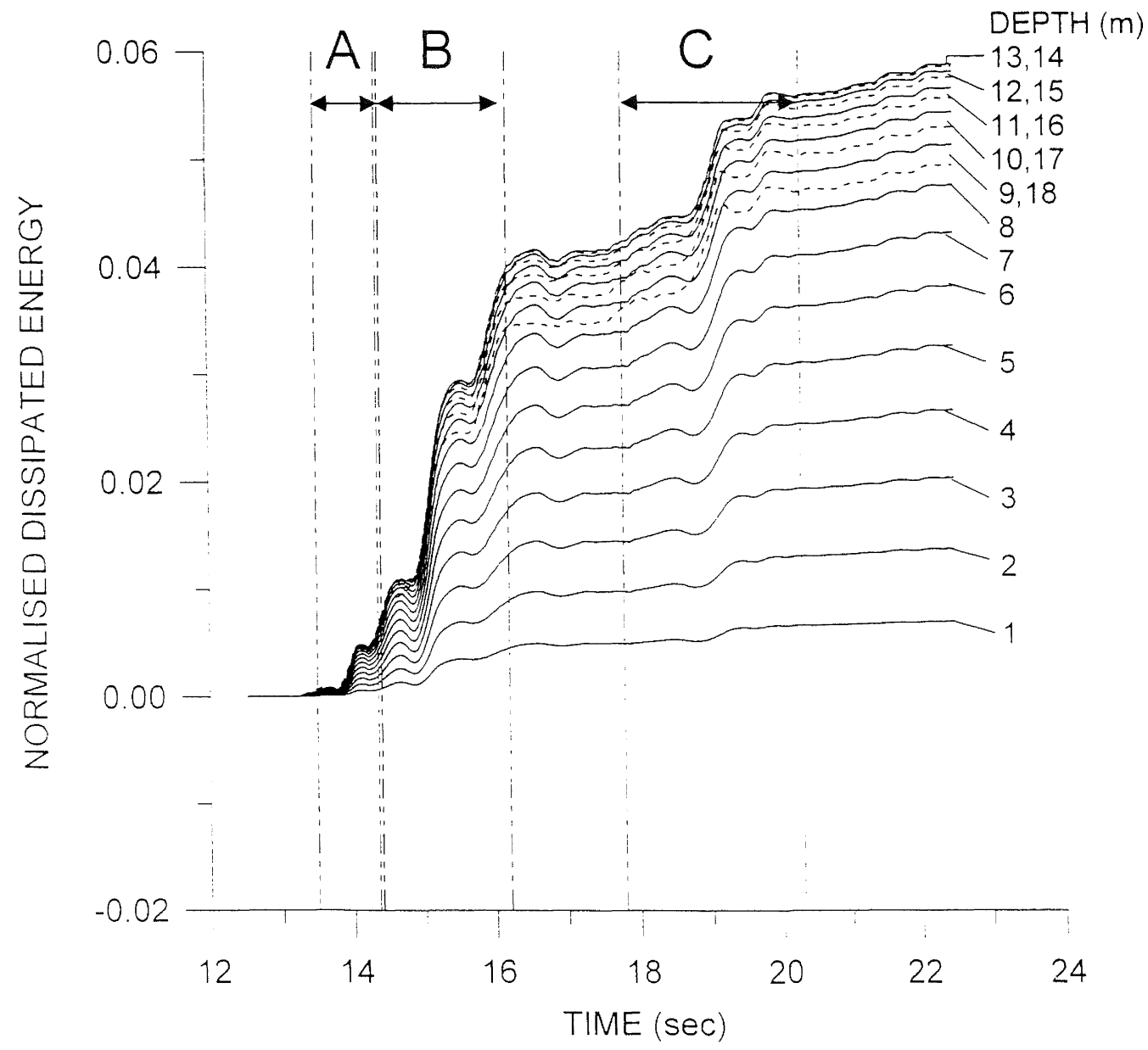

FIGURE 11: Time histories of dissipated energy density normalised by overburden effective stress. Each curve corresponds to a different depth. Solid lines are used for depths between 1 metre and 13 metres. Dashed lines are used for depths between 14 metres and 18 metres. The time intervals $A, B$ and $C$ correspond to the times for the stress-strain curves in Figures 9 and 10. 


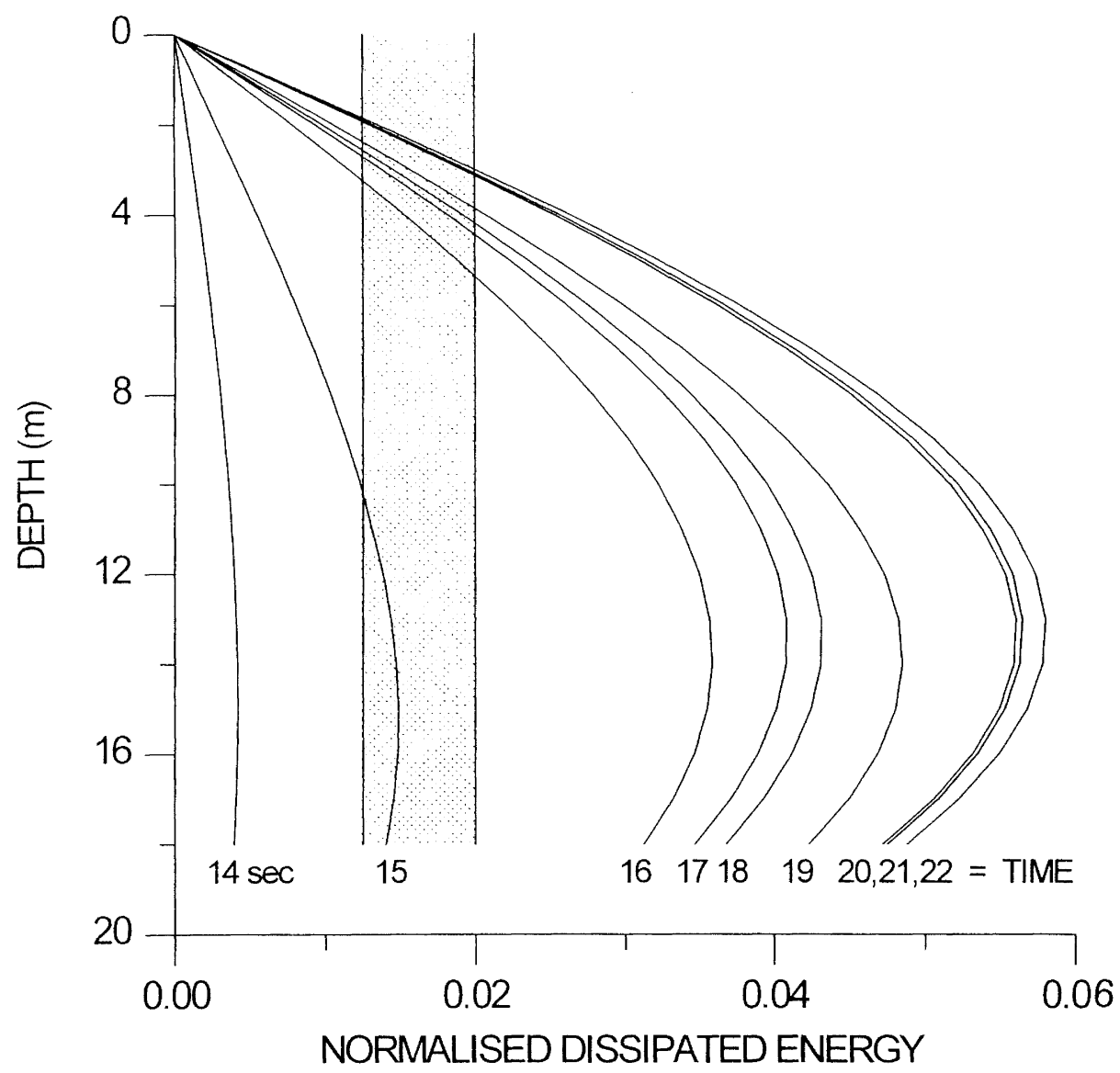

FIGURE 12: Profiles of normalised dissipated energy density versus depth for various times.

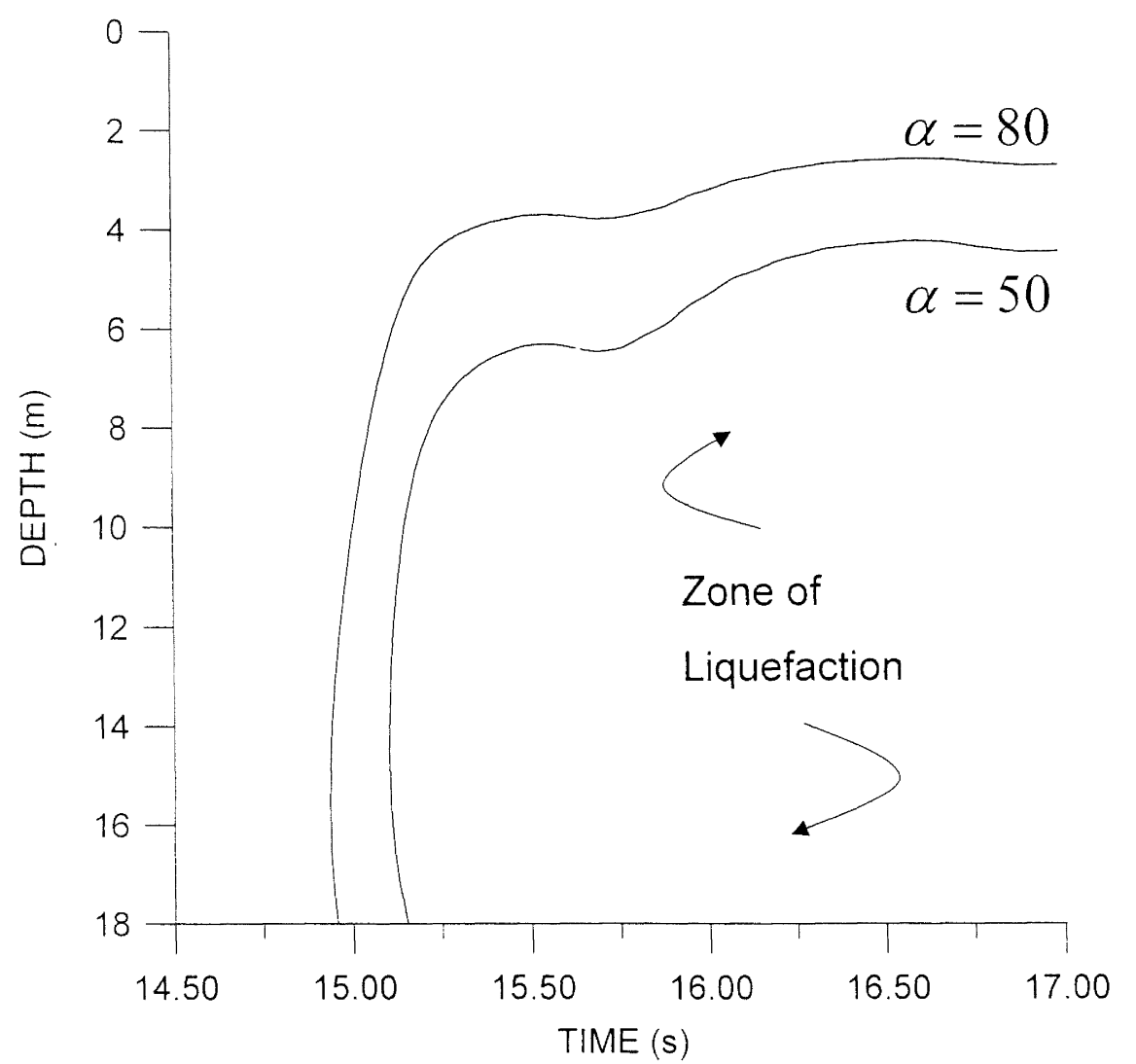

FIGURE 13: Growth of the zone of liquefaction for two values of the parameter $\alpha$. 